Supporting Information

\title{
Photofragmentation Pathways for Gas-Phase Lanthanide Tris(isopropylcyclopentadienyl) Complexes
}

Yulun Han, ${ }^{\dagger}$ Dmitri S. Kilin, ${ }^{\dagger}$ P. Stanley May, ${ }^{\dagger}$ Mary T. Berry, ${ }^{*}{ }^{\dagger}$ and Qingguo Meng ${ }^{*}, \S$

${ }^{\dagger}$ Department of Chemistry, University of South Dakota, Vermillion, South Dakota 57069, United States

${ }^{\ddagger}$ Department of Chemistry and Biochemistry, North Dakota State University, Fargo, North Dakota 58108, United States

${ }^{\S}$ Shenyang Institute of Automation, Guangzhou, Chinese Academy of Sciences, Guangzhou 511458, China 


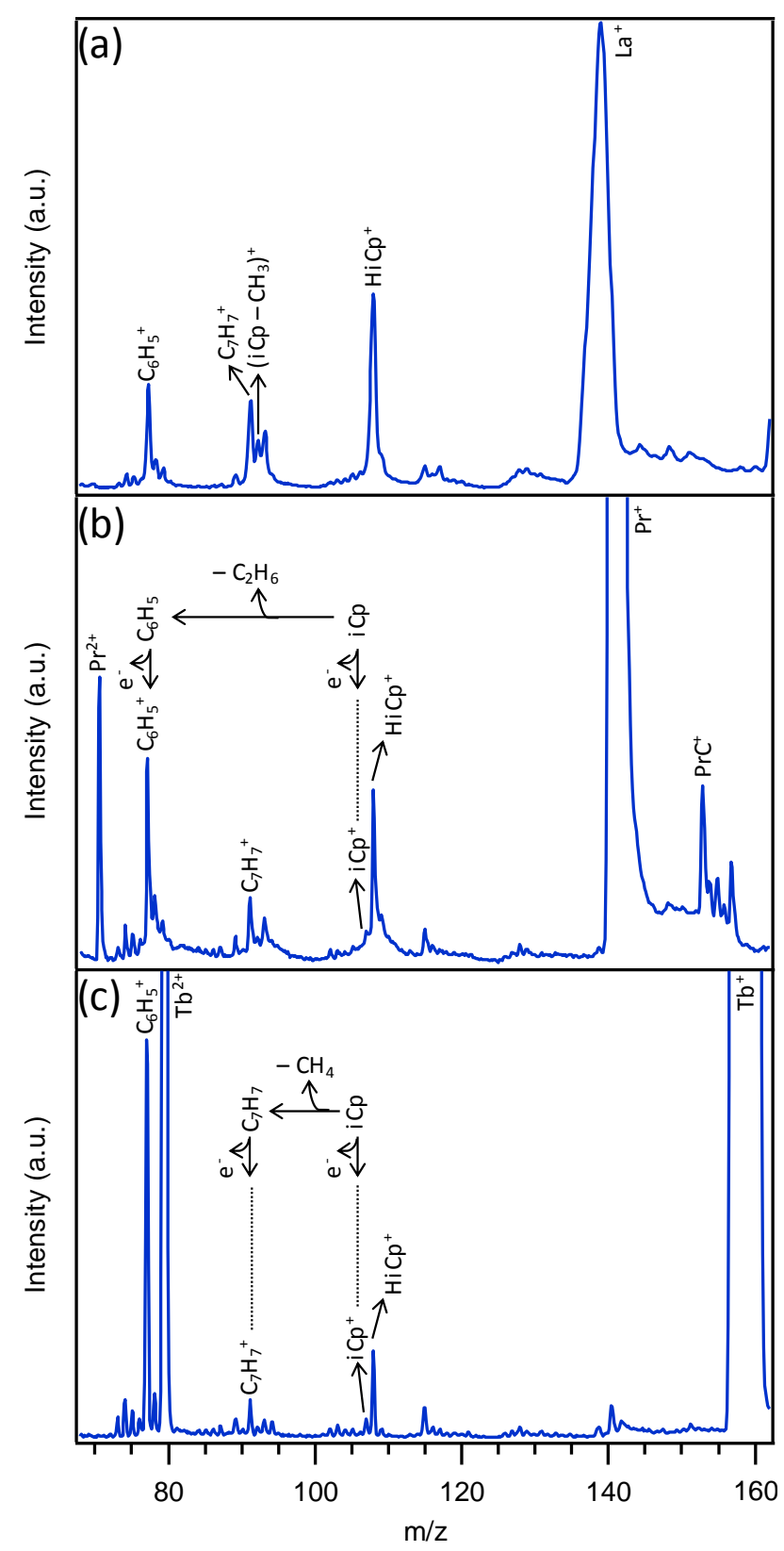

Figure S1. PI-TOF mass spectra of (a) $\mathrm{La}(\mathrm{iCp})_{3}$, (b) $\mathrm{Pr}(\mathrm{iCp})_{3}$, and (c) $\mathrm{Tb}(\mathrm{iCp})_{3}$ precursors photoexcited at $266 \mathrm{~nm}$ in the $\mathrm{m} / \mathrm{z}$ range of $68 \sim 162$. 


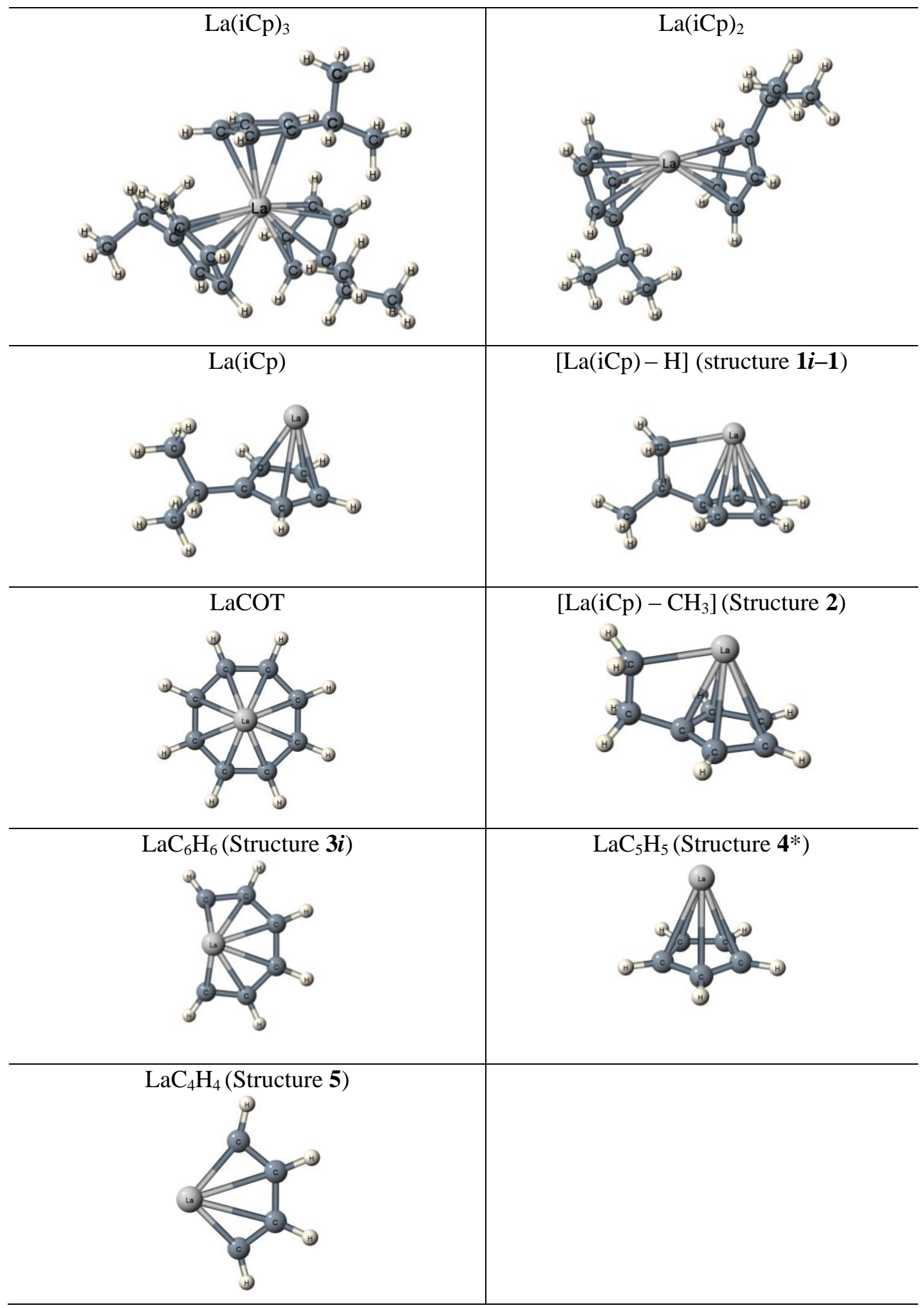

Figure S2. Snapshots of models after geometry optimization used as the starting point in the TDESMD simulations. 
Table S1. Proposed molecular structures for $\mathrm{LnC}_{8} \mathrm{H}_{10}$ (feature 1), $\mathrm{LnC}_{8} \mathrm{H}_{8}$ (feature $\mathbf{1}^{\prime}$ ), and $\mathrm{LnC}_{8} \mathrm{H}_{6}$ (feature $\mathbf{1}^{\prime \prime}$ ) after geometry optimization. Structures labeled with $\boldsymbol{i}$ are alternative structures.

Features Images of snapshots after geometry $\quad$ Molecular structures $\quad$ Energy (eV) optimization

1
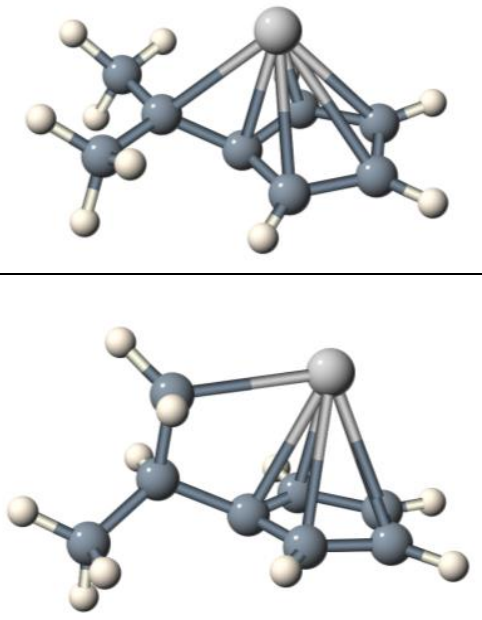

$1 i-1$

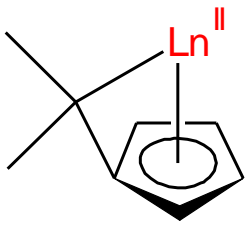

$-112.19$

$-112.14$
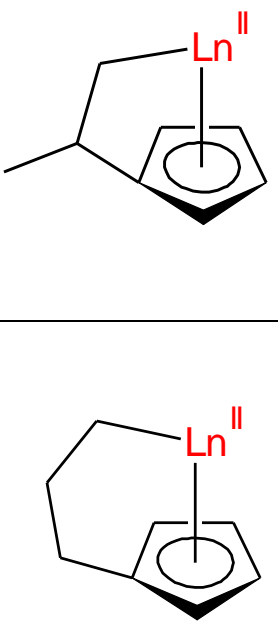

$-112.42$

$1 i-2$
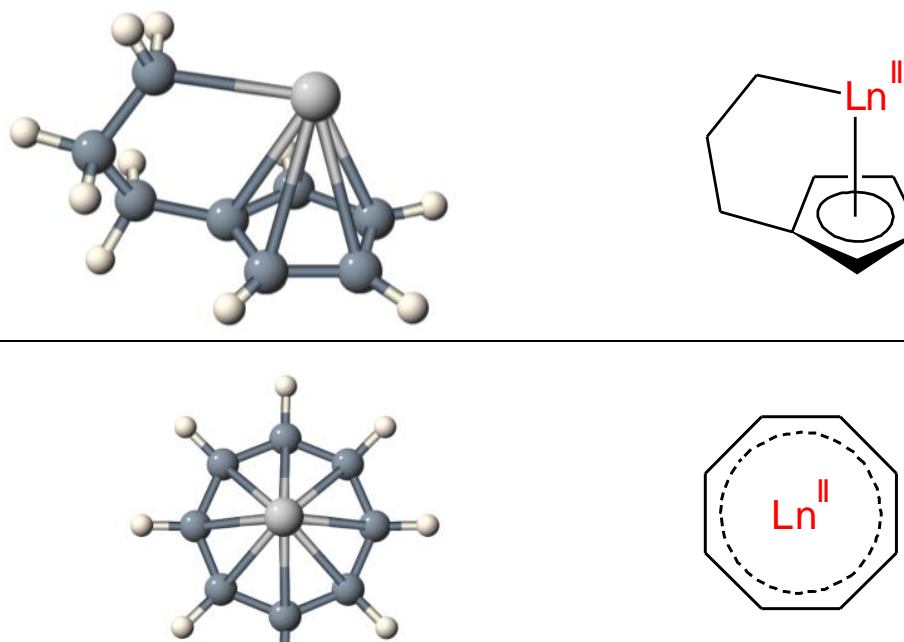

$-105.05$

$1^{\prime}$

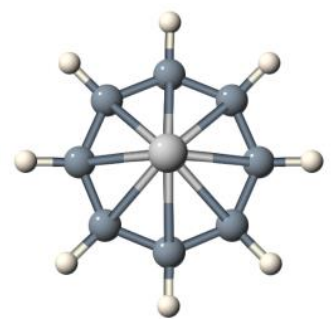

$-104.24$

1' $i-1$
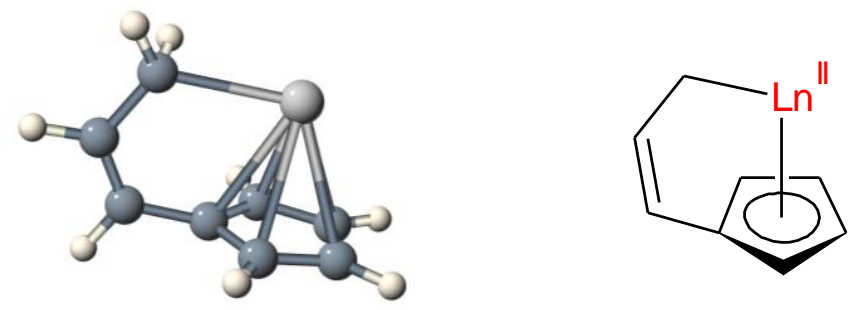
Features Images of snapshots after geometry $\quad$ Molecular structures $\quad$ Energy $(\mathrm{eV})$ optimization
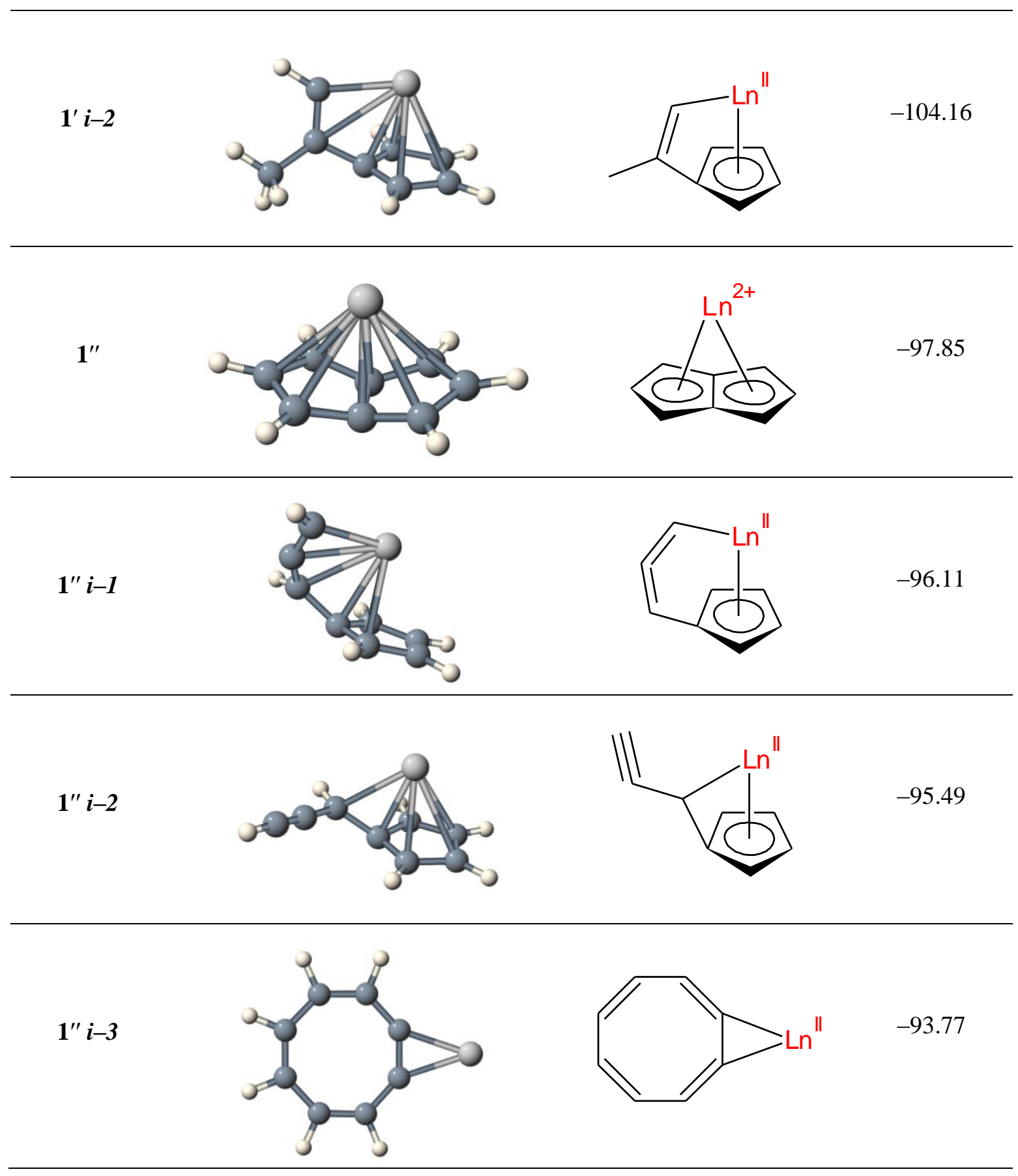


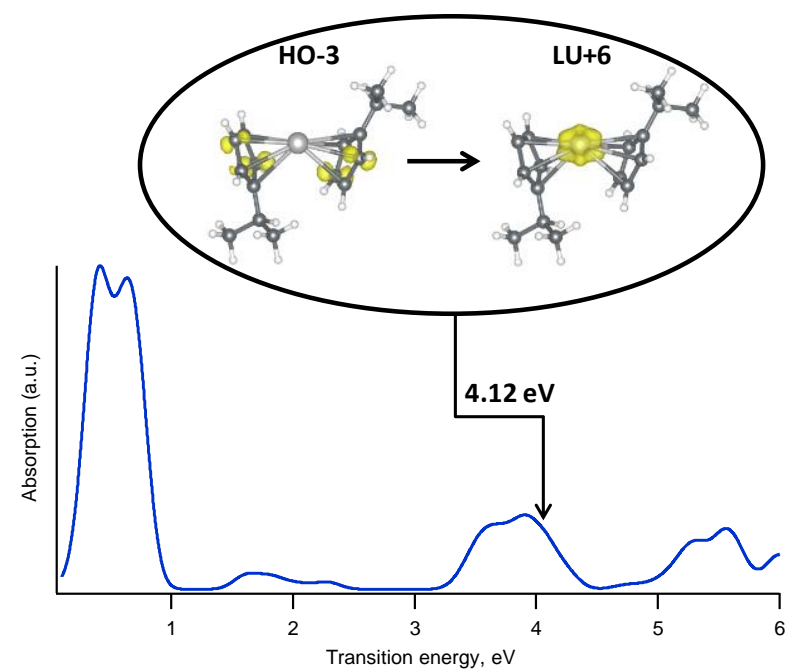

Figure S3. The absorption spectrum for unperturbed $\mathrm{La}(\mathrm{iCp})_{2}$ computed by ground state DFT and partial charge density for selected Kohn-Sham orbitals. The transition energy of HO-3 $\rightarrow$ LU+6 is about $4.12 \mathrm{eV}$. This transition is a typical ligand-to-metal charge-transfer transition and is explored in the TDESMD simulation. The silver, gray, and white spheres represent $\mathrm{La}, \mathrm{C}$, and $\mathrm{H}$, respectively. Isosurfaces are in yellow. 


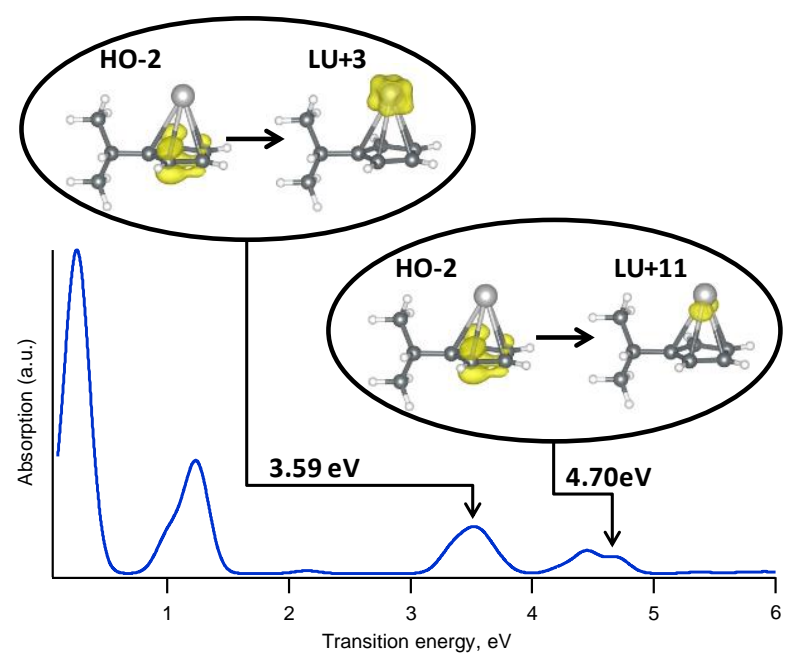

Figure S4. The absorption spectrum for unperturbed $\mathrm{La}(\mathrm{iCp})$ computed by ground state DFT and partial charge density for selected Kohn-Sham orbitals. The transition energies of HO-2 $\rightarrow$ LU+3 and HO-2 $\rightarrow$ LU+11 are about 3.59 and $4.70 \mathrm{eV}$, respectively. These transitions are typical ligand-to-metal charge-transfer transitions and are explored in TDESMD simulations. The silver, gray, and white spheres represent $\mathrm{La}, \mathrm{C}$, and $\mathrm{H}$, respectively. Isosurfaces are in yellow. 


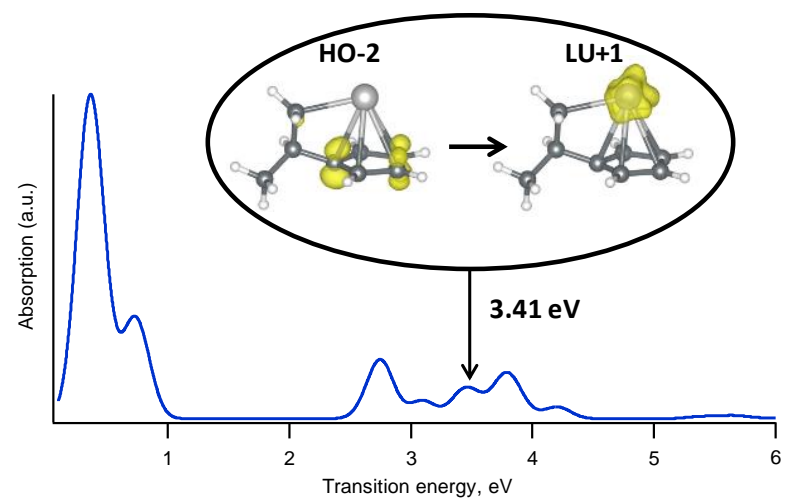

Figure S5. The absorption spectrum for unperturbed $[\mathrm{La}(\mathrm{iCp})-\mathrm{H}]$ computed by ground state DFT and partial charge density for selected Kohn-Sham orbitals. The transition energy of HO-2 $\rightarrow \mathrm{LU}+1$ is $3.41 \mathrm{eV}$. This transition is a typical ligand-to-metal charge-transfer transition and is explored in the TDESMD simulation. The silver, gray, and white spheres represent $\mathrm{La}, \mathrm{C}$, and $\mathrm{H}$, respectively. Isosurfaces are in yellow. 


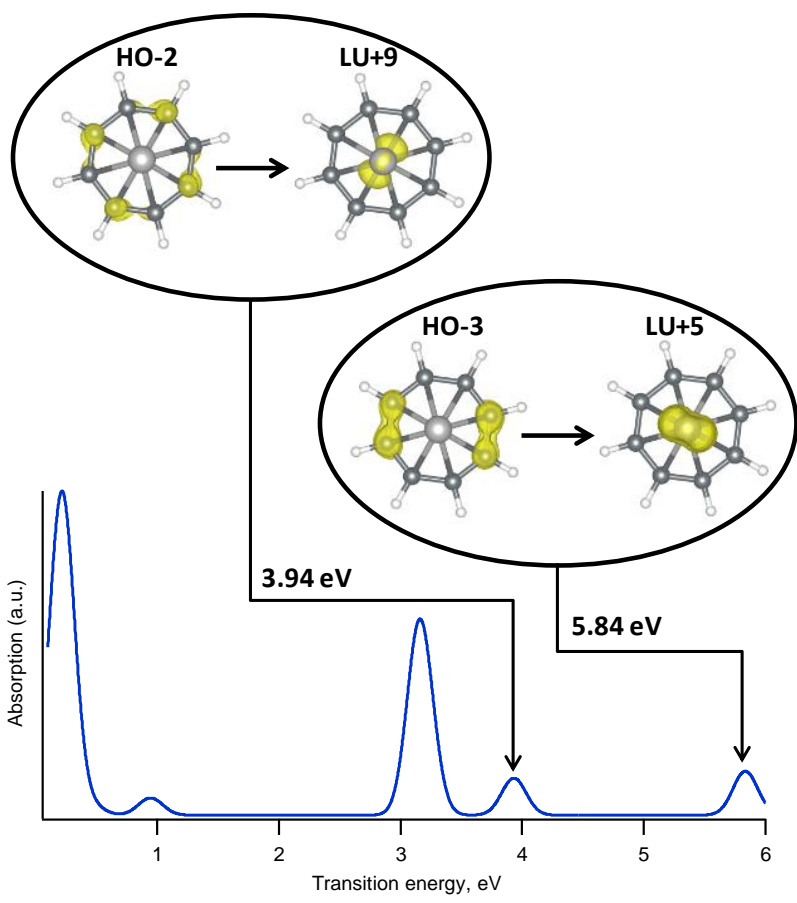

Figure S6. The absorption spectrum for unperturbed LaCOT computed by ground state DFT and partial charge density for selected Kohn-Sham orbitals. The transition energies of HO-2 $\rightarrow$ LU+9 and HO-3 $\rightarrow$ LU+5 are about $3.94 \mathrm{eV}$ and $5.84 \mathrm{eV}$, respectively. These transitions are typical ligand-to-metal charge-transfer transitions and are explored in TDESMD simulations. The silver, gray, and white spheres represent $\mathrm{La}, \mathrm{C}$, and $\mathrm{H}$, respectively. Isosurfaces are in yellow. 


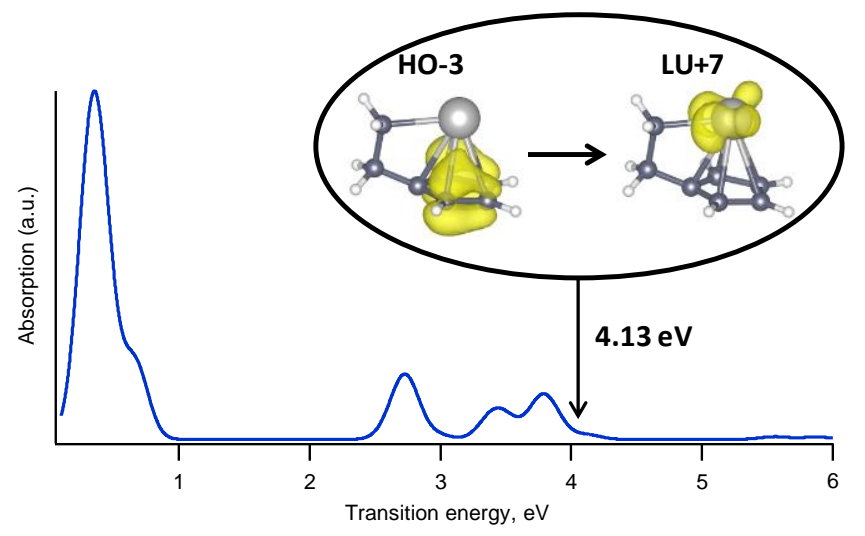

Figure S7. The absorption spectrum for unperturbed $\left[\mathrm{La}(\mathrm{iCp})-\mathrm{CH}_{3}\right]$ computed by ground state DFT and partial charge density for selected Kohn-Sham orbitals. The transition energy of HO-3 $\rightarrow \mathrm{LU}+7$ is $4.13 \mathrm{eV}$. This transition is a typical ligand-to-metal charge-transfer transition and is explored in the TDESMD simulation. The silver, gray, and white spheres represent $\mathrm{La}, \mathrm{C}$, and $\mathrm{H}$, respectively. Isosurfaces are in yellow. 


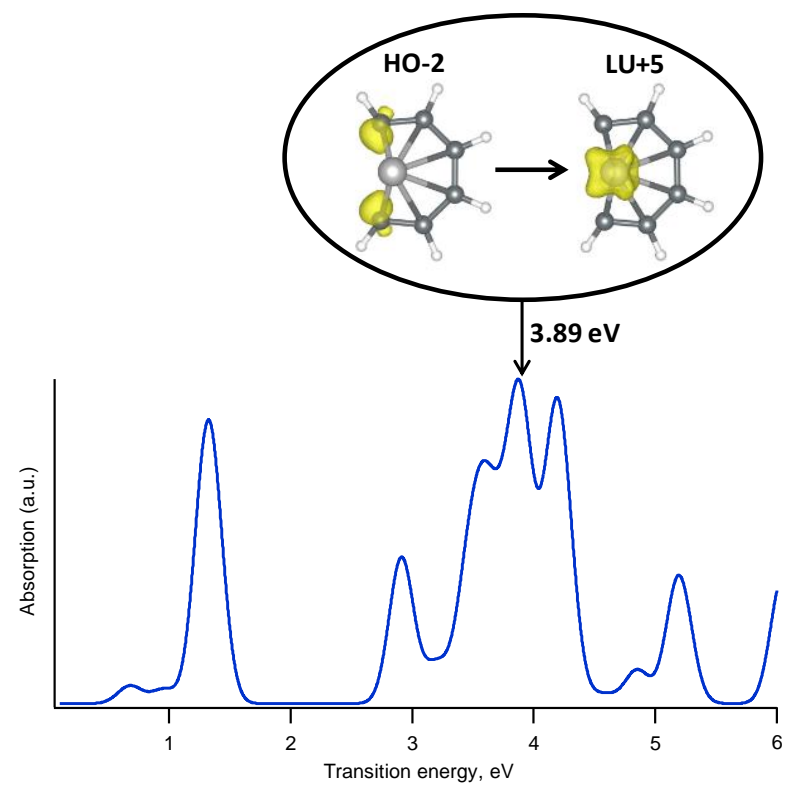

Figure S8. The absorption spectrum for unperturbed $\mathrm{LaC}_{6} \mathrm{H}_{6}$ computed by ground state DFT and partial charge density for selected Kohn-Sham orbitals. The transition energy of HO-2 $\rightarrow$ LU+5 is $3.89 \mathrm{eV}$. This transition is a typical ligand-to-metal charge-transfer transition and is explored in the TDESMD simulation. The silver, gray, and white spheres represent $\mathrm{La}, \mathrm{C}$, and $\mathrm{H}$, respectively. Isosurfaces are in yellow. 


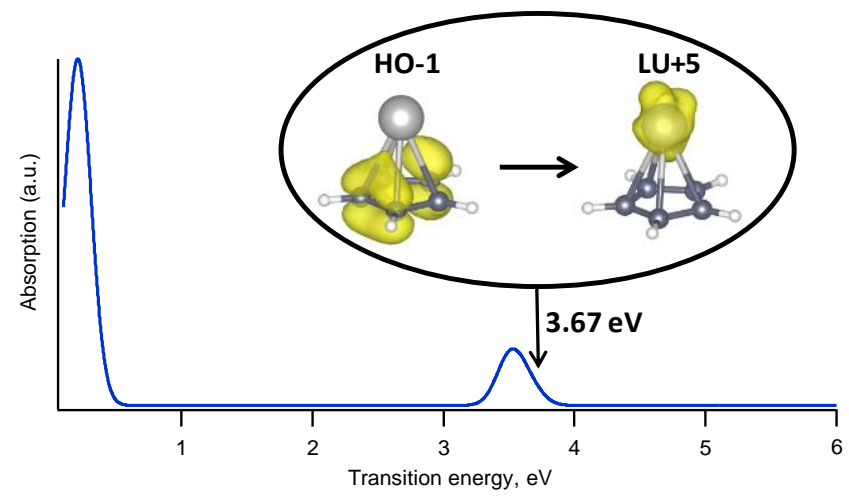

Figure S9. The absorption spectrum for unperturbed $\mathrm{LaC}_{5} \mathrm{H}_{5}$ computed by ground state DFT and partial charge density for selected Kohn-Sham orbitals. The transition energy of HO-1 $\rightarrow$ LU+5 is $3.67 \mathrm{eV}$. This transition is a typical ligand-to-metal charge-transfer transition and is explored in the TDESMD simulation. The silver, gray, and white spheres represent La, C, and $\mathrm{H}$, respectively. Isosurfaces are in yellow. 


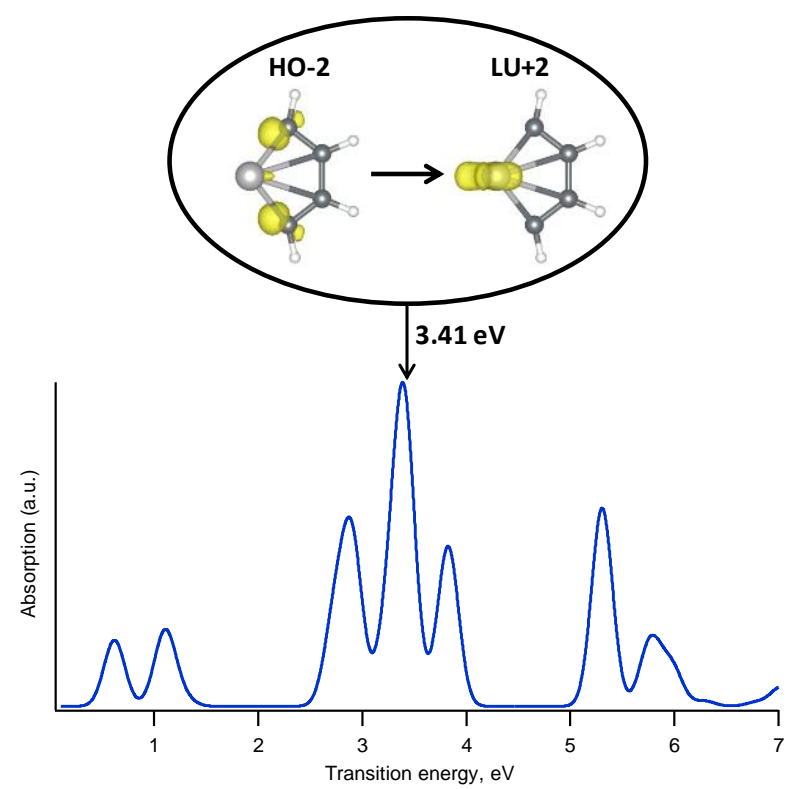

Figure S10. The absorption spectrum for unperturbed $\mathrm{LaC}_{4} \mathrm{H}_{4}$ computed by ground state DFT and partial charge density for selected Kohn-Sham orbitals. The transition energy of HO-2 $\rightarrow$ $\mathrm{LU}+2$ is $3.41 \mathrm{eV}$. This transition is a typical ligand-to-metal charge-transfer transition and is explored in the TDESMD simulation. The silver, gray, and white spheres represent $\mathrm{La}, \mathrm{C}$, and $\mathrm{H}$, respectively. Isosurfaces are in yellow. 
Table S2. Computed ligand-binding energies and ionization potentials for the $\mathrm{La}(\mathrm{iCp})_{\mathrm{n}}$ complexes

\begin{tabular}{l|c|c|c|c}
\hline & $\mathrm{La}(\mathrm{iCp})_{3}$ & $\mathrm{La}(\mathrm{iCp})_{2}$ & $\mathrm{La}(\mathrm{iCp})$ & $\mathrm{La}^{0}$ \\
\hline La oxidation state & +3 & +2 & +1 & 0 \\
\hline iCp binding energy, $E_{B}^{i C p}(\mathrm{eV})$ & 3.8 & 4.0 & 4.6 & - \\
\hline iCp binding energy, $E_{B}^{i C p^{-}}(\mathrm{eV})$ & 5.6 & 6.1 & 9.3 & - \\
\hline Ionization potential, $E_{I P}(\mathrm{eV})$ & 5.0 & 2.7 & 3.0 & 5.6 \\
\hline Bare metal ionization potential, $E_{I P}(\mathrm{eV})$ & - & 19.2 & 11.1 & 5.6 \\
\hline iCp Electron affinity, $E_{E A}(\mathrm{eV})$ & 0.9 & - & - & - \\
\hline
\end{tabular}

\section{Competition in temporal order of photofragmentation and photoionization}

To illustrate the photochemistry under discussion we have created a series of qualitative adiabatic potential energy curves for each of the complexes $\mathrm{La}(\mathrm{iCp})_{3}$, $\mathrm{La}(\mathrm{iCp})_{2}$, and $\mathrm{La}(\mathrm{iCp})$. The curve shapes, giving potential energy as a function of metalligand distance, are calculated from an electrostatic attraction of point charges added to a Lennard-Jones 6-12 potential, the latter component representing the repulsive forces at short distances as well as any attraction due to dispersion forces, e.g. $\mathrm{La}(0)+\mathrm{iCp}$, or to weak covalency for the reduced metal.

$$
V(r)=\frac{q_{1} q_{2}}{4 \pi \epsilon_{0} r}+4 D_{e}\left[\left(\frac{\sigma}{r}\right)^{12}-\left(\frac{\sigma}{r}\right)^{6}\right]+C
$$

The parameters, $\mathrm{C}, D_{e}$, and $\sigma$, are chosen such that the qualitative curves match the DFT calculations for ionization energies, ligand binding energies, bond lengths, etc. as illustrated for $\mathrm{La}(\mathrm{iCp})$ below. The charges $q_{1}$ and $q_{2}$ are charge on the iCp ligand (0 or 1) and the net charge on the metal containing component $(0,+1,+2$, or +3$)$. 


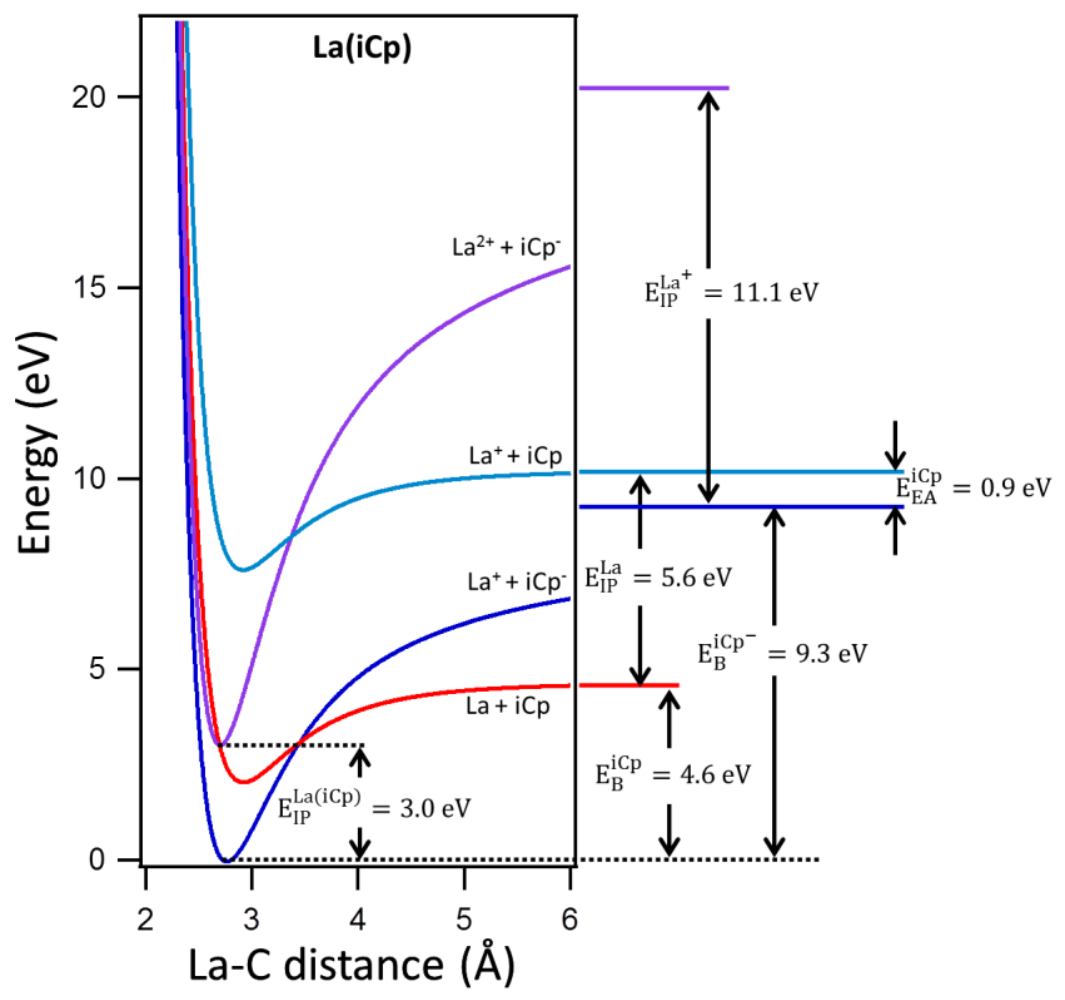

Figure S11. Qualitative adiabatic potential energy curves of $\mathrm{La}(\mathrm{iCp})$ complexes. The dark blue, red, purple, and sky blue curves indicate the ground state, charge transfer state, cationic state, and cationic charge transfer state, respectively. The horizontal lines outside the diagram indicate the energy at which the metal and ligand are separated at infinite distance.

In the experiments under discussion, the metal-organic complexes are subject to short laser pulses (6 ns) with power densities on the order of $\mathrm{GW} / \mathrm{cm}^{2}$ and photon energies on the order of $2-5 \mathrm{eV}$. This discussion applies particularly to metal-organic complexes for which ligand-to-metal charge-transfer (LMCT) is energetically favored by a resonance stabilized ligand radical. Examples include the $\beta$-diketonate and cyclopentadienyl ligands.

In these experiments, the laser both fragments the complexes and creates ions that are detected by the mass spectrometer. It has been argued that the fragmentation patterns 
observed in the mass spectrum are dominated by mechanisms whereby neutral molecules fragment, yielding neutral fragments which are subsequently photoionized and detected by the mass spectrometer, in contrast to the $70 \mathrm{eV}$ EI mass spectrum wherein, highenergy electron impact results in a high-energy molecular ion which subsequently fragments. For example, the ligand-stripping model for photofragmentation has been represented as follows.

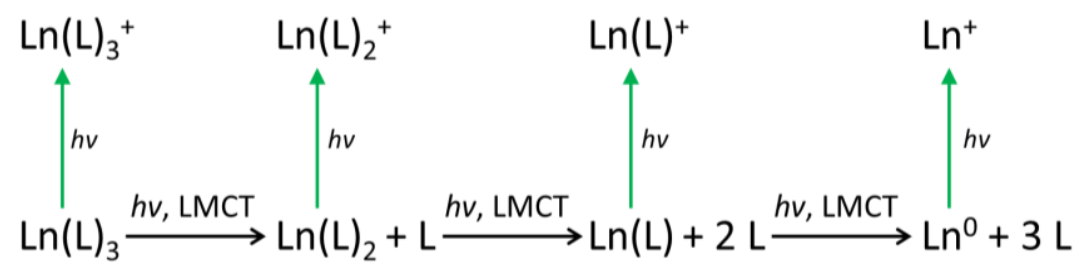

The fragmentation steps are each promoted by strong optical absorbance, inducing a transition to the repulsive wall of a ligand-to-metal charge-transfer (LMCT) state as illustrated below for the case of $\mathrm{La}(\mathrm{iCp})_{3}$. This transition generally occurs at 4 to $5 \mathrm{eV}$ and is thus accessible by one or two photons. 

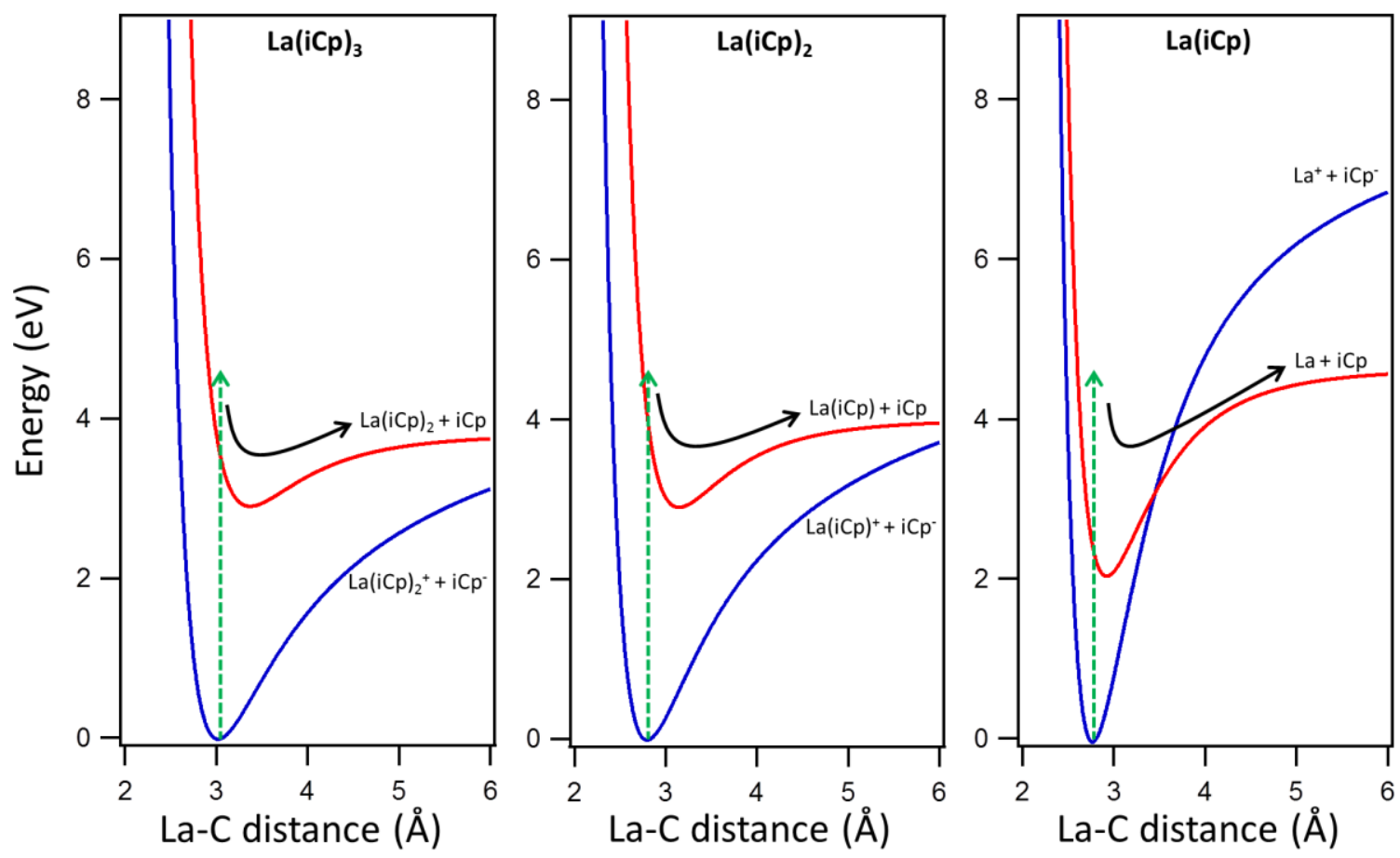

Figure S12. Qualitative adiabatic potential energy curves of $\mathrm{La}(\mathrm{iCp})_{\mathrm{n}}$ complexes. The dark blue and red curves indicate the ground state and charge transfer state, respectively. The green arrows indicate the photoexcitation at $266 \mathrm{~nm}$. The complexes are excited to the repulsive wall of the LMCT state, leading to the reduction of the metal and rapid ligand dissociation. 

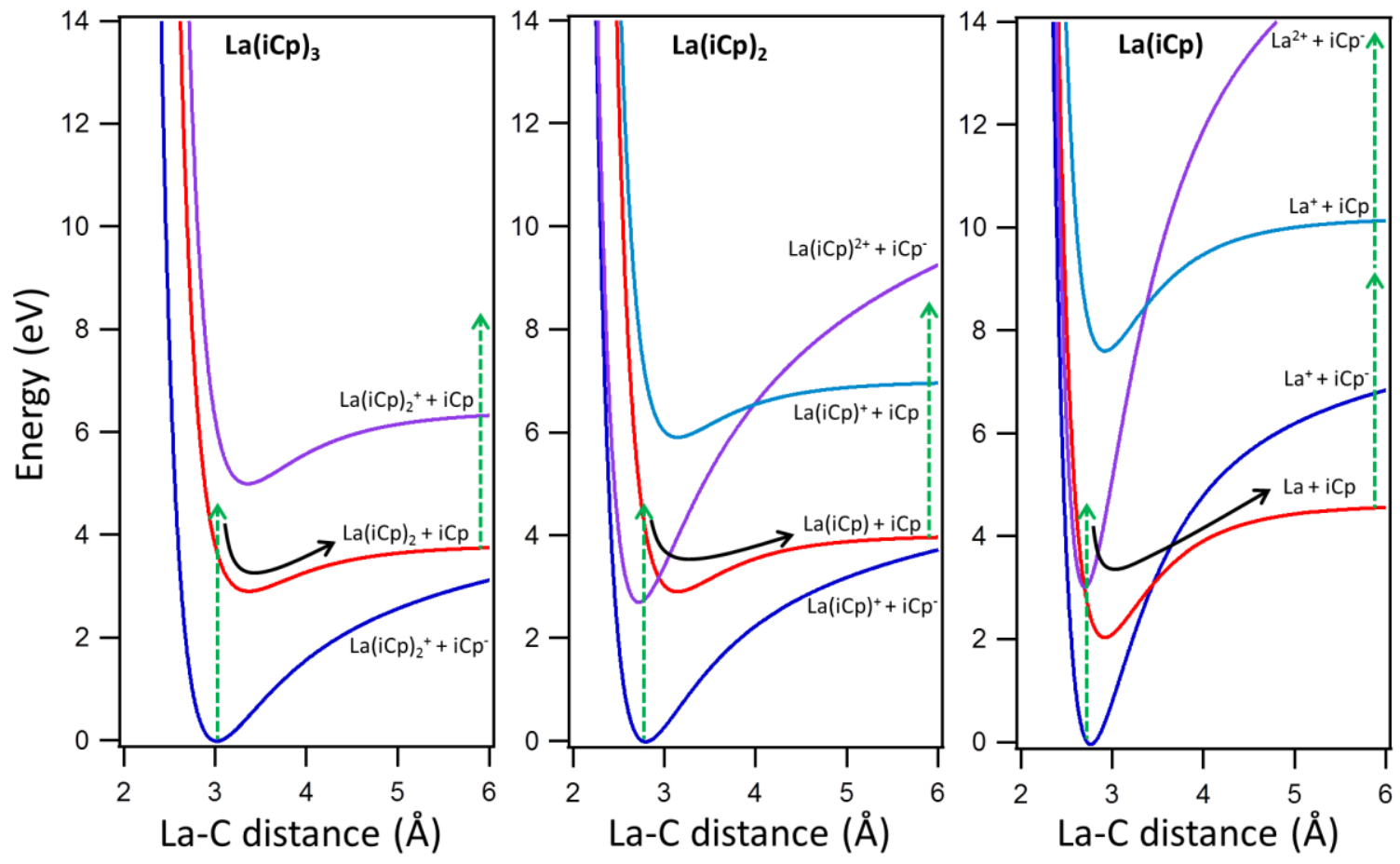

Figure S13. Qualitative adiabatic potential energy curves for $\mathrm{La}(\mathrm{iCp})_{\mathrm{n}}$ complexes. The dark blue, red, purple, and sky blue curves indicate the ground state, charge transfer state, cationic state, and cationic charge transfer state, respectively. The green arrows indicate the photoexcitation at 266 $\mathrm{nm}$. The complexes are excited to the repulsive wall of the LMCT state, leading to the reduction of the metal and rapid ligand dissociation (curved black arrow). The neutral fragments are subsequently photoionized by absorbance of additional one or two photons, when the energy exceeds the lower dissociation limit for the cation (purple or sky blue).

That this process of fragmentation of neutrals, accompanied by reduction of the metal, does occur is supported by REMPI experiments which show the signature of $\mathrm{Eu}^{0}$ excited states when monitoring the signal for $\mathrm{Eu}^{+}$in the photofragmentation of $\operatorname{Eu}(\text { thd })_{3}$. $^{1,2}$

The importance of the charge transfer state in promoting ligand ejection is illustrated in the photodissociation of Eu(hfac) ${ }_{3}$ diglyme. $^{3}$ The beta-diketonate, hfac $^{-}$ 
anions, have low-energy LMCT interactions, whereas the neutral diglyme ligands do not. In these experiments, the fragmentation patterns showed $\mathrm{Eu}(\mathrm{hfac})_{3}$ diglyme ${ }^{+}$, $\mathrm{Eu}(\mathrm{hfac})_{2}$ diglyme $^{+}, \mathrm{Eu}(\mathrm{hfac})$ diglyme $^{+}$, and EuFdiglyme ${ }^{+}$, but no Eu(hfac $)_{\mathrm{n}}^{+}$, the complex easily ejecting or fragmenting the initially-anionic ligands while retaining the neutral polyether.

In another observation, femtosecond (500 fs) laser excitation of $\mathrm{Co}(\mathrm{acac})_{3}$ resulted in two species observed in the mass spectrum, major $\mathrm{Co}(\mathrm{acac})_{3}{ }^{+}$and minor $\mathrm{Co}(\mathrm{acac})_{2}{ }^{+}$with no other fragments observed, whereas nanosecond (6 ns) laser excitation led to significant fragmentation, with the spectrum dominated by $\mathrm{Co}^{+}$, despite conditions of much lower fluence. ${ }^{4}$ We have interpreted this as, under short-pulse conditions the laser pulse is not around long enough to cause sequential photodissociation steps or to ionize the products of photodissociation since dissociation occurs on a time scale of picoseconds.

Within the model we have proposed, using $\mathrm{La}(\mathrm{iCp})_{3}$ curves in the illustration, two processes are in competition: (1) a coherent two-photon process which produces the cation, $\mathrm{La}(\mathrm{iCp})_{3}{ }^{+}$, above the dissociation limit for $\mathrm{La}(\mathrm{iCp})_{3}{ }^{+} \rightarrow \mathrm{La}(\mathrm{iCp})_{2}{ }^{+}+\mathrm{iCp}$, and (2) a single photon process causing the neutral dissociation, $\mathrm{La}(\mathrm{iCp})_{3} \rightarrow \mathrm{La}(\mathrm{iCp})_{2}+\mathrm{iCp}$, where $\mathrm{La}(\mathrm{iCp})_{2}$ may be subsequently photoionized to $\mathrm{La}(\mathrm{iCp})_{2}{ }^{+}$. These alternatives are illustrated in Figure S14 below. Process (1) is favored by the high fluence of the femtosecond excitation, whereas process (2) is favored at lower fluence if the pulse duration is sufficiently long. 


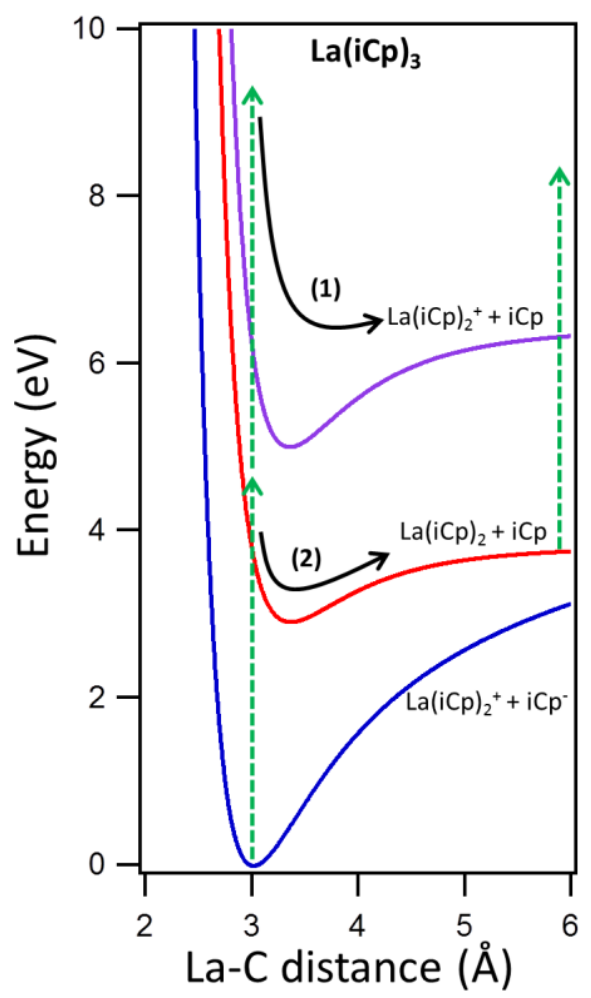

Figure S14. Qualitative adiabatic potential energy curves of $\mathrm{La}(\mathrm{iCp})_{3}$ complexes. The dark blue, red, and purple curves indicate the ground state, charge transfer state, and cationic state, respectively. The green arrows indicate the photoexcitation at $266 \mathrm{~nm}$. Process (1) is a coherent two-photon process which produces the cation, $\mathrm{La}(\mathrm{iCp})_{3}{ }^{+}$, above the dissociation limit for $\mathrm{La}(\mathrm{iCp})_{3}{ }^{+} \rightarrow \mathrm{La}(\mathrm{iCp})_{2}{ }^{+}+\mathrm{iCp}$. Process (2) is a single photon process causing the neutral dissociation, $\mathrm{La}(\mathrm{iCp})_{3} \rightarrow \mathrm{La}(\mathrm{iCp})_{2}+\mathrm{iCp}$, where $\mathrm{La}(\mathrm{iCp})_{2}$ may be subsequently photoionized to $\mathrm{La}(\mathrm{iCp})_{2}^{+}$.

Using this interpretation, in the $\mathrm{Co}(\mathrm{acac})_{3}$ experiments, the high-fluence femtosecond excitation results in a multiphoton photoionization, producing $\mathrm{Co}(\mathrm{acac}){ }_{3}{ }^{+}$, some fraction of which fragments to $\mathrm{Co}(\mathrm{acac})_{2}{ }^{+}+$acac. Notice that in this process there is no reduction of the $\mathrm{Co}(\mathrm{III})$ which retains its +3 oxidation state throughout. Under the much lower fluence ns excitation, Grun et al. found the spectrum was dominated almost entirely by $\operatorname{Co}(\mathrm{I})$, where the metal had clearly been reduced in the photodissociation process. ${ }^{4}$ 
Using strongly-focused, ns pulses for photodissociation of $\operatorname{Ln}(\mathrm{L})_{3}$ we have also observed mass spectra dominated by bare $\operatorname{Ln}(\mathrm{I})$, with $\operatorname{Ln}(\mathrm{II})$ and then $\operatorname{Ln}(\mathrm{III})$ appearing as the laser power density was increased. To observe the metal organic fragments reported in this work, the laser fluence was purposely reduced to optimize signal for these reaction intermediates.

The question arises, more generally, regarding whether the products of photoionization might also be subject to further fragmentation and if so, how much of this is reflected in the mass spectrum. Certainly, from Hess' Law, the total energy required for a particular ion's formation is the same regardless of the order of fragmentation and ionization, so any difference in the preferred order of the two processes relates to the probability of optical absorbance into states that promote the chemistry in question. Figure $\mathbf{S 1 5}$ below illustrates the potential photochemistry of the metal-organic cations. 

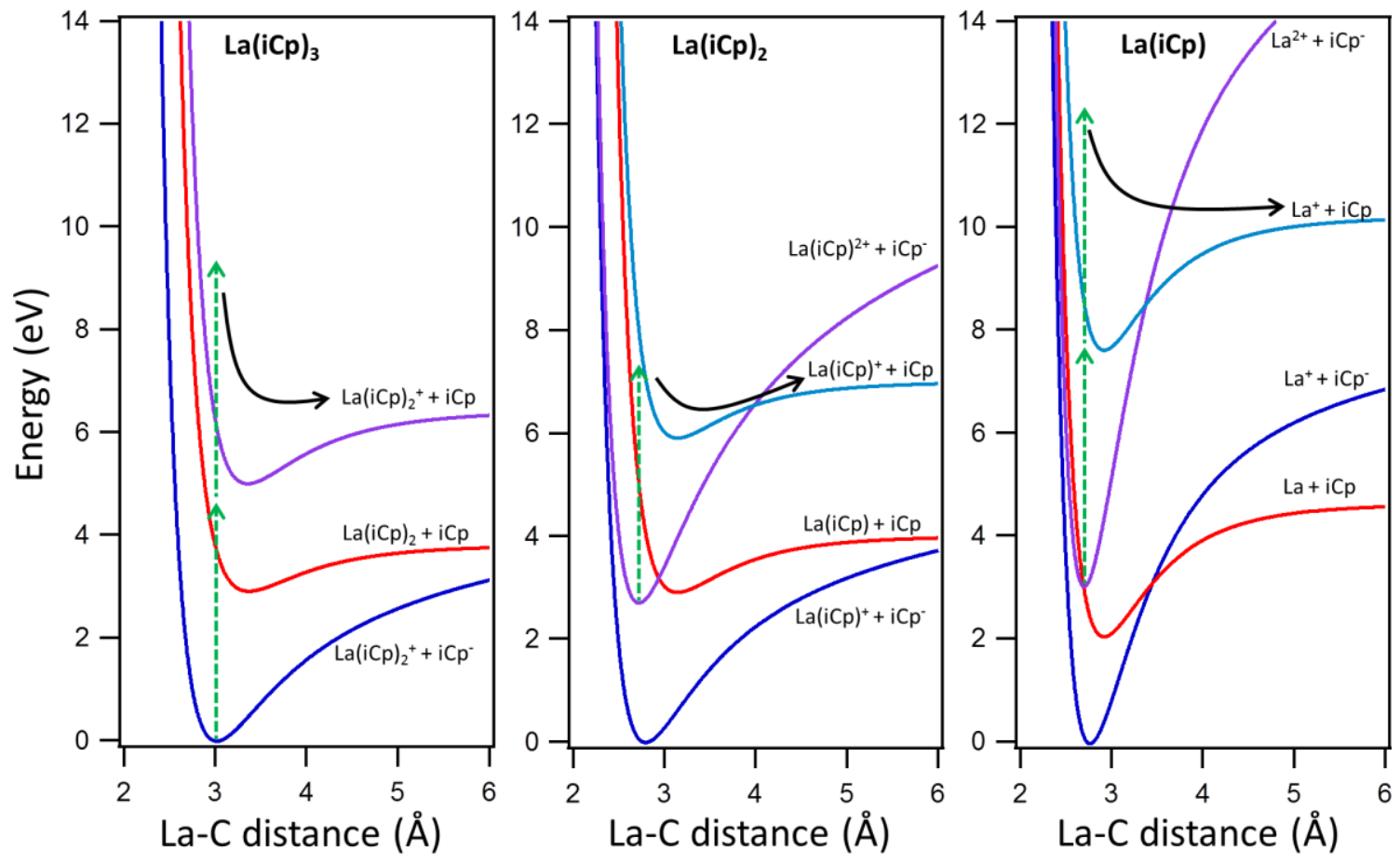

Figure S15. Qualitative adiabatic potential energy curves of $\mathrm{La}(\mathrm{iCp})_{\mathrm{n}}$ complexes. The dark blue, red, purple, and sky blue curves indicate the ground state, charge transfer state, cationic state, and cationic charge transfer state, respectively. The green arrows indicate photoexcitation of the cation at $266 \mathrm{~nm}$.

The first panel in Figure $\mathbf{S 1 5}$ for $\mathrm{La}(\mathrm{iCp})_{3}$ has been discussed above; neutral photofragmentation is likely favored over photoionization under ns pulse excitation. The next two panels illustrate how the cations can also undergo excitation to LMCT states, with the resultant expected dissociation. In the second panel, where $\mathrm{La}(\mathrm{iCp})^{+}$is the product of the photoreaction of $\mathrm{La}(\mathrm{iCp})_{2}{ }^{+}$, the dominant path would then mostly be determined by the branching ratio in the previous step. That is, by the competition between:

$\mathrm{La}(\mathrm{iCp})_{2} \rightarrow \mathrm{La}(\mathrm{iCp})+\mathrm{iCp}$ (excitation to red curve)

vs.

$\mathrm{La}(\mathrm{iCp})_{2} \rightarrow \mathrm{La}(\mathrm{iCp})_{2}{ }^{+}+\mathrm{e}^{-}$(excitation to purple curve). 
The first of these is favored somewhat by the Franck-Condon overlap engendered by the shift in the minimum of the LMCT state potential which results from the reduction in electrostatic attraction. See Figure S13.

The graphical case for the third panel for $\mathrm{La}(\mathrm{iCp})^{+} \rightarrow \mathrm{La}^{+}+\mathrm{iCp}$ is less obvious. However, the very weak appearance of $\mathrm{La}(\mathrm{iCp})^{+}$in the spectrum, whereas some ions might be expected to be trapped by the requirement of two photons for photodissociation of the cation, argues against ionization preceding dissociation. Furthermore, the strength of the $\operatorname{Ln}(0)$ REMPI signal as reported in the literature ${ }^{1,2}$ supports the importance of the path in the previous step for photodissociation of the neutral, suggesting the dominance of:

$\mathrm{La}(\mathrm{iCp}) \rightarrow \mathrm{La}^{0}+\mathrm{iCp}$ (excitation to red curve)

vs.

$\mathrm{La}(\mathrm{iCp}) \rightarrow \mathrm{La}(\mathrm{iCp})^{+}+\mathrm{e}^{-}$(excitation to purple curve)

Table S3. Computed energies for $\mathrm{La}(\mathrm{Cp})$ and $\mathrm{LaC}_{3} \mathrm{H}_{3}$ complexes

\begin{tabular}{l|c|c|c|c|c}
\hline & $\mathrm{La}^{\mathrm{I}}(\mathrm{Cp})$ & $\mathrm{La}^{0}(\mathrm{Cp})$ & $\mathrm{La}^{\mathrm{II}}(\mathrm{Cp})^{+}$ & $\mathrm{La}^{\mathrm{I}}(\mathrm{Cp})^{+}$ & $\mathrm{Cp}$ \\
\hline Dissociation energy, $E_{D}(\mathrm{eV})^{a}$ & 4.5 & 3.8 & 4.8 & 3.8 & 3.3 \\
\hline Ionization potential, $E_{I P}(\mathrm{eV})$ & 2.6 & - & - & - & - \\
\hline Electron affinity, $E_{E A}(\mathrm{eV})$ & - & - & - & - & 1.8 \\
\hline \hline & $\mathrm{La}^{\mathrm{I}} \mathrm{C}_{3} \mathrm{H}_{3}$ & $\mathrm{La}^{0} \mathrm{C}_{3} \mathrm{H}_{3}$ & $\mathrm{La}^{\mathrm{II}} \mathrm{C}_{3} \mathrm{H}_{3}{ }^{+}$ & $\mathrm{La}^{\mathrm{I}} \mathrm{C}_{3} \mathrm{H}_{3}{ }^{+}$ & $\mathrm{C}_{3} \mathrm{H}_{3}$ \\
\hline Binding energy, $E_{B}(\mathrm{eV})^{b}$ & 8.8 & 2.0 & 17.0 & 2.0 & - \\
\hline Ionization potential, $E_{I P}(\mathrm{eV})$ & 2.9 & - & - & - & - \\
\hline Electron affinity, $E_{E A}(\mathrm{eV})$ & - & - & - & - & 0.9 \\
\hline
\end{tabular}

${ }^{a} E_{D}$ is defined, for example, as $E_{D}^{\mathrm{La}^{\mathrm{I}}(\mathrm{Cp})}=E_{\left[\mathrm{La}^{\mathrm{I}} \mathrm{C}_{3} \mathrm{H}_{3}\right]}+E_{\left[\mathrm{C}_{2} \mathrm{H}_{2}\right]}-E_{[\mathrm{La}(\mathrm{Cp})]}$

${ }^{b} E_{B}$ is defined, for example, as $E_{B}^{\mathrm{La}^{\mathrm{I}} \mathrm{C}_{3} \mathrm{H}_{3}}=E_{\left[\mathrm{La}^{+}\right]}+E_{\left[\mathrm{C}_{3} \mathrm{H}_{3}{ }^{-}\right]}-E_{\left[\mathrm{La}^{\mathrm{I}} \mathrm{C}_{3} \mathrm{H}_{3}\right]}$ 
To apply the same types of arguments to the ligand cracking chemistry we have considered the simple cyclopentadienyl complex, $\mathrm{La}(\mathrm{Cp})$, and the well-studied dissociation of the $\mathrm{C}_{5} \mathrm{H}_{5}$ moiety into $\mathrm{C}_{3} \mathrm{H}_{3}$ and $\mathrm{C}_{2} \mathrm{H}_{2}$ fragments. Figure $\mathbf{S 1 6}$ shows qualitative adiabatic potential energy curves for the $\mathrm{La}(\mathrm{Cp})$ complex, where the ordinate now represents the cracking of a cyclopentadienyl ligand $\mathrm{C}_{5} \mathrm{H}_{5}$ into $\mathrm{C}_{3}$ and $\mathrm{C}_{2}$ fragments. The curve shapes are again represented by a Lennard-Jones potential, $V(r)=4 D_{e}\left[(\sigma / r)^{12}\right.$ $\left.(\sigma / r)^{6}\right]+C$, where the parameters, $C, D_{e}$, and $\sigma$ are chosen such that the qualitative curves match the DFT calculations for ionization energies, ligand binding energies, bond lengths, etc. Note the energies of $\mathrm{La}(\mathrm{Cp})$ complex, represented by the minima of the curves, are obtained the same way as illustrated in Figure S11. The vertical positions of curves (determined by the parameter, $C$ ) are shifted to match the energies of $\mathrm{LaC}_{3} \mathrm{H}_{3}$ complexes. The metal-ligand binding energies of $\mathrm{La}^{0} \mathrm{C}_{3} \mathrm{H}_{3}$ and $\mathrm{La}^{\mathrm{I}} \mathrm{C}_{3} \mathrm{H}_{3}{ }^{+}$are estimated as $2.0 \mathrm{eV}$. The dissociation energy of the $\mathrm{Cp}$ radical $\left(\mathrm{C}_{5} \mathrm{H}_{5} \rightarrow \mathrm{C}_{3} \mathrm{H}_{3}+\mathrm{C}_{2} \mathrm{H}_{2}\right)$ has been reported as $3.3 \mathrm{eV} .^{5}$ Activation barriers along the dissociation coordinate are not represented in these simple Lennard-Jones curves. Reference 5 illustrates the barriers for the $\mathrm{Cp}$ radical, free of metal binding. 


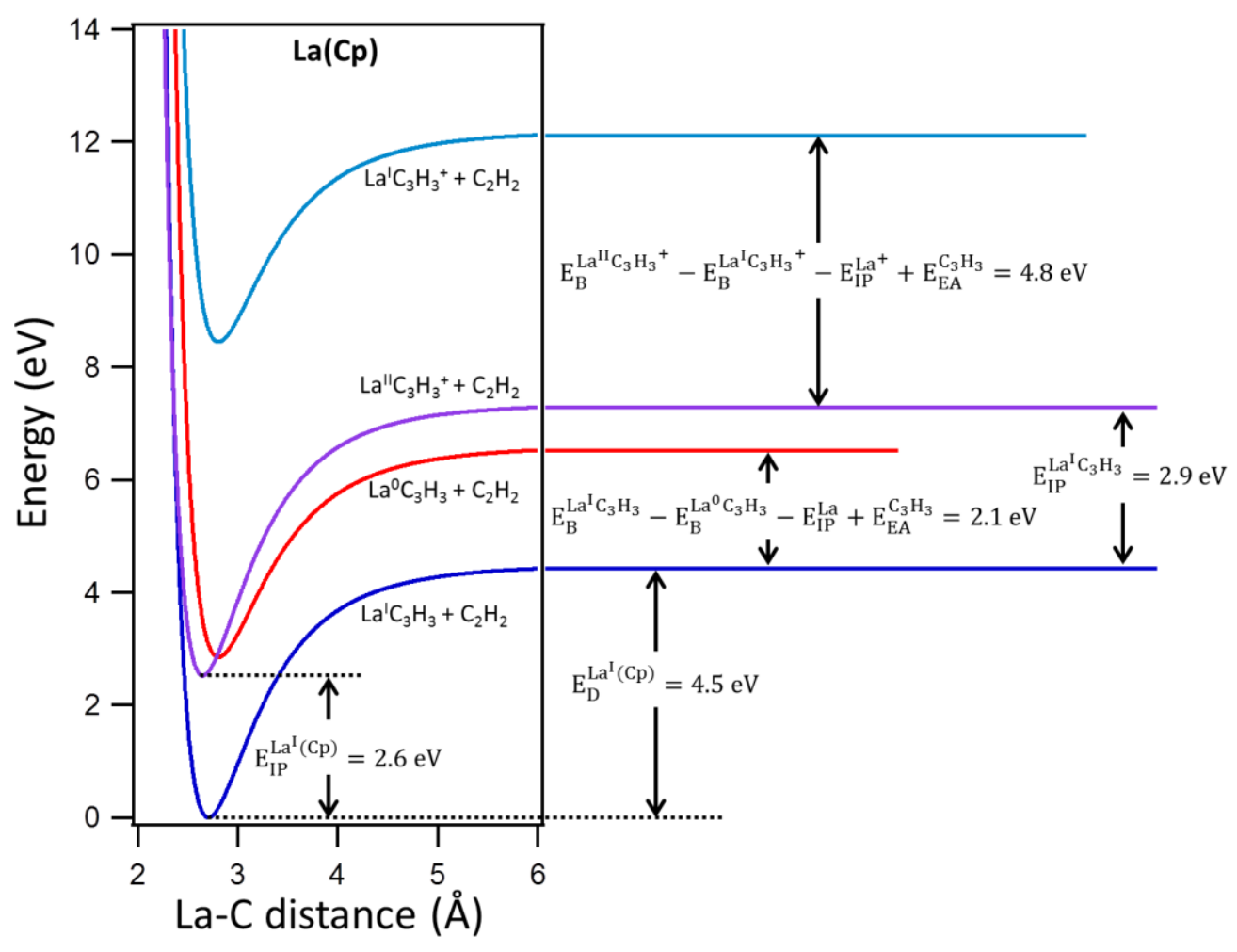

Figure S16. Qualitative adiabatic potential energy curves for fragmentation of $\mathrm{La}(\mathrm{Cp})$ complexes. The dark blue, red, purple, and sky blue curves indicate the ground state, charge transfer state, cationic state, and cationic charge transfer state, respectively. The horizontal lines outside the diagram indicate the energy at which the metal-containing fragment and the $\mathrm{C}_{2} \mathrm{H}_{2}$ fragment are separated at infinite distance.

Figure S17 suggests that excitation into the charge transfer state (red curve) could result in coupling into the continuum of the ground state adiabatic curve (dark blue curve) during the dissociation process. Alternatively, a single photon could ionize the complex (excitation to purple curve) but then dissociation would require a two-photon transition to the sky blue LMCT state or a single-photon transition to the dissociation continuum of the purple curve, the latter transition lacking the advantage of any strong optical absorbance. 

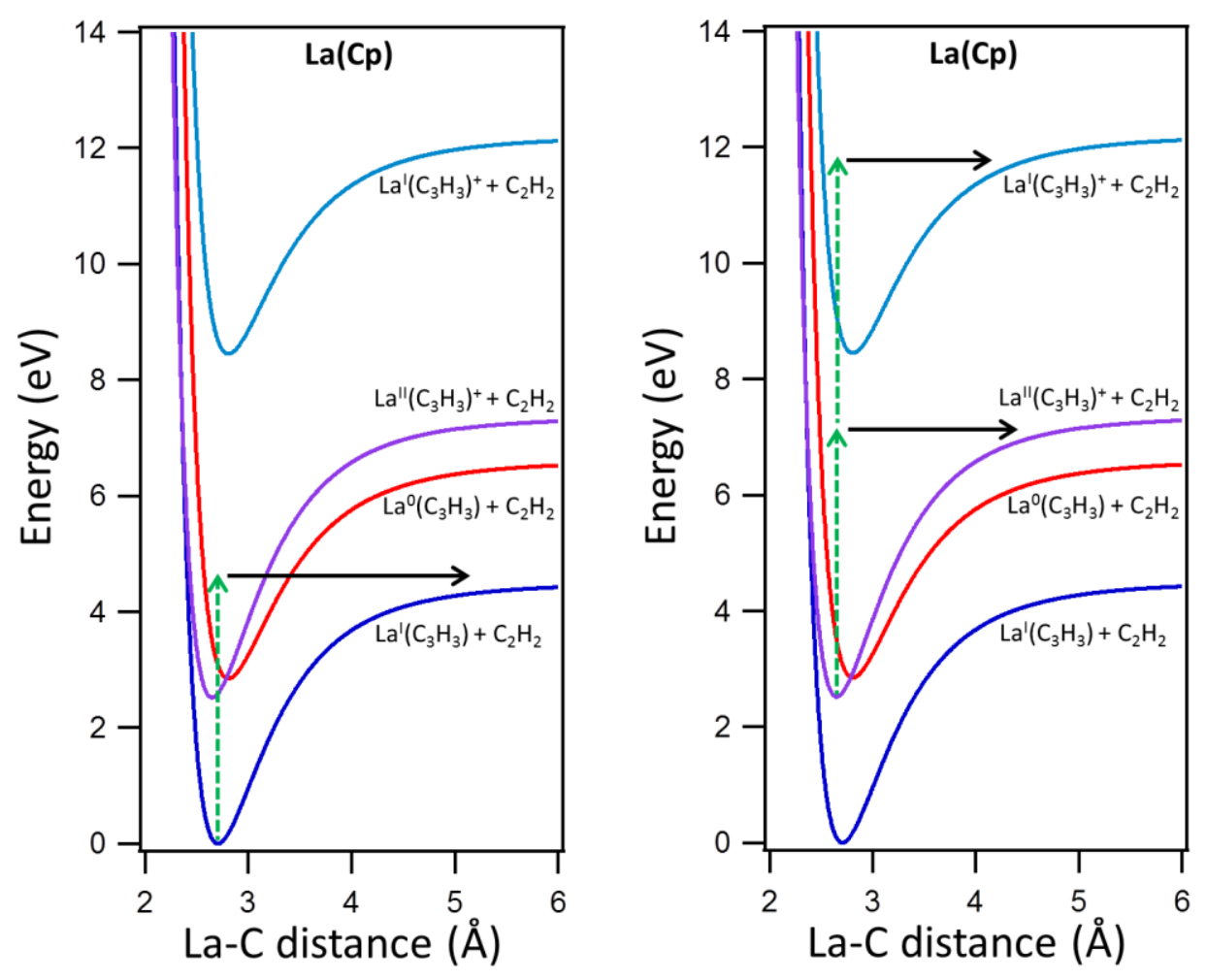

Figure S17. Qualitative adiabatic potential energy curves for fragmentation of the $\mathrm{La}(\mathrm{Cp})$ complexes. The dark blue, red, purple, and sky blue curves indicate the ground state, charge transfer state, cationic state, and cationic charge transfer state, respectively. The green arrows indicate photoexcitation at $266 \mathrm{~nm}$. The black arrows represent cracking of the $\mathrm{Cp}$ ligand to eject a neutral $\mathrm{C}_{2} \mathrm{H}_{2}$ fragment. The left panel shows one-photon dissociation of the neutral fragments $\mathrm{La}(\mathrm{Cp}) \rightarrow \mathrm{LaC}_{3} \mathrm{H}_{3}+\mathrm{C}_{2} \mathrm{H}_{2}$ and the right panel illustrates alternative dissociation of the cation $\mathrm{La}(\mathrm{Cp})^{+} \rightarrow \mathrm{LaC}_{3} \mathrm{H}_{3}^{+}+\mathrm{C}_{2} \mathrm{H}_{2}$.

In this paper we have simulated photofragmentation of neutral species using TDESMD. The evidence suggests that this is the dominant pathway under our experimental conditions, though dissociation of the cationic species may contribute to some features. 


\section{References:}

(1) F. P. Ow, M. T. Berry, P. S. May and J. I. Zink, J. Phys. Chem. A, 2006, 110, 7751-7754.

(2) F. P. Ow, M. T. Berry, P. S. May and J. I. Zink, J. Phys. Chem. A, 2007, 111, 4144-4149.

(3) Q. Meng, R. J. Witte, P. S. May and M. T. Berry, Chem. Mater., 2009, 21, 5801-5808.

(4) C. Grun, R. Heinicke, C. Weickhardt and J. Grotemeyer, Int. J. Mass Spectrom., 1999, 185187, 307-318.

(5) L. V. Moskaleva and M. C. Lin, J. Comput. Chem., 2000, 21, 415-425. 